\title{
Investigating the Impact of Misinformation Sources on Health Issues: Implications for Public Health
}

\author{
Marianna ISAAKIDOU ${ }^{\mathrm{a}, 1}$, Emmanouil ZOULIAS ${ }^{\mathrm{b}}$ and Marianna DIOMIDOUS ${ }^{\mathrm{a}}$ \\ ${ }^{\text {a }}$ Faculty of Nursing, National and Kapodistrian University of Athens, Athens, Greece \\ ${ }^{b}$ Health Informatics Laboratory, Faculty of Nursing, National and Kapodistrian \\ University of Athens, Athens, Greece
}

\begin{abstract}
The aim of this work is to shortly provide the public with an overview about fake news and artificial intelligence (AI) technology. Especially in our days, where there is a high speed of spreading news, the impact of fake news on public health is crucial and the development of valid and effective means of technology to support the provision of safe and trustworthy information about public health issues is vital. The role of informatics in health area is profoundly important and AI in public health, so people will be able to distinguish the genuine information from the fake one.
\end{abstract}

Keywords. Fake news, Misinformation, Public Health, Artificial Intelligence

\section{Introduction}

Since the early stages of internet and even more later through Social Media, another "epidemic" or "pandemic" appeared the word "Infodemic", consisted by words information and epidemic, which means "epidemic of information" [1]. According to UNESCO's definition, misinformation/disinformation is the false information that is spread under the guise of news. The term "misinformation" refers to information that is false, but not created with the purpose of harming someone, while the term "disinformation" refers to information that is false and intentionally created to harm a person, company or country [2]. Furthermore, misinformation can be also due to an interpretation of true facts, like the case of COVID-19 [3].

\section{Methods}

The Internet, Social Media, Social Networks, and technology have a strong influence on health decisions. There are cases that help spread rumors, misinformation, or even more they can undermine public health policies. Given the lack of knowledge about the use of social media for health, there is a need for complex interdisciplinary tools, methods, and guidelines to help public to understand how to use social networks and other sources on

\footnotetext{
${ }^{1}$ Corresponding Author, Marianna Isaakidou, PhD cand. Faculty of Nursing, School of Health Sciences, National and Kapodistrian University of Athens, Athens, Greece; E-mail: marianis@nurs.uoa.gr.
} 
Public Health issues. Education and knowledge, a better understanding of social media, and the recognition of various sources of misinformation will give health authorities new tools to help make decisions at global, national, local, and corporate levels.

\section{Results}

The role of technology and informatics in health area is profoundly important supporting a wide range of healthcare products including medical devices, information technology, like EHR, medical imagining, life support systems, and many more [4]. AI systems affect broadly daily human life at all society levels. AI is growing rapidly and tremendously, worldwide and healthcare area has been affected by in early stages of AI. The use of AI systems in Health Care has great potentialities that might change the daily practice and even change the basic definitions in the health context [5]. Effective AI methods to detect or prevent misinformation could be tools like machine learning, deep learning, chatbots, interactive mobile applications, apps, social media communities against the phenomenon [6].

\section{Discussion and Conclusions}

The behavior of social media users and how they spread health information has already presented in various studies [7]. In addition to that, the role of "fake news" on public health issues has been recognized as catastrophic globally [8]. The role of modern Public Health specialists should be to reduce "fake news" and repeal the disastrous side effects. AI technology appeared to be a useful means of defense. Tools, like chatbots, apps, can evaluate the quality of information. Furthermore, AI technology supports the personalized medicine for those searching for health information or even to support patients with personalized clinical advice, treatment, pharmacological, or even surgical support. AI systems can be trained continuously with fake information, malicious data, and many more untrusted data [9].

\section{References}

[1] Morphy F. Pseudography reading: History of fake news, Available at: https://www.maxmag.gr https://www.maxmag.gr/afieromata/fake-news/, Accessed 7 August, 2020.

[2] Ireton C, Posetti J. Journalism, Fake News and Disinformation: A Handbook for Journalism Education and Training. France: UNESCO Series on Journalism Education; 2018.

[3] Tanya L. Confronting Misinformation. Scientific American. Nov 2020;323(5):28-29.

[4] International Network of Agencies for Health Technology Assessment (INAHTA). HTA glossary, Available at: http://htaglossary.net/HomePage, Accessed 7 August, 2020.

[5] eHealth Initiative. Artificial Intelligence in Healthcare. USA: eHealth Initiative Report; Nov 2018.

[6] Baxter A. Report: Understanding AI in healthcare essential to stop fake news. AI in Healthcare. 2019.

[7] Waszak PM, Kasprzycka-Waszak W, Kubanek A. The spread of medical fake news in social mediaThe pilot quantitative study. Health Policy Technol. 2018;7:115-118.

[8] Krishna A, Thompson TL. Misinformation About Health: A Review of Health Communication and Misinformation Scholarship. Am. Behav. Sci. 2019;0002764219878223.

[9] Gómez-González E, Gómez E. Artificial Intelligence in Medicine and Healthcare: applications, availability, and societal impact. Luxembourg: Publications Office of the European Union, EUR 30197 EN; 2020. ISBN 978-92-76-18454-6. doi:10.2760/047666, JRC120214. 